\title{
A MEMÓRIA E O SUJEITO: IMPASSES E CONTRIBUIÇÕES DA LEITURA EM LINGUA ESTRANGEIRA *
}

\author{
Márcia Atálla Pietroluongo **
}

Resumo: No jogo de instauração de sentidos intrínseco à leitura, o sujeito-leitor inscreve seits modos de apreensão do mundo e sua bistória, marcados pela ideologia. Tal processo confronta-se necessariamente com dificuldades particulares, quando se trata da leitura em língua estrangeira. Esse trabalbo pretende discutir particularmente a interpretaçăo do interdiscurso, como um dos aspectos fundamentais da produção significante, estabelecida a partir da tensão entre lugares socioculturais marcados pela alteridade.

Todo texto supõe a inscrição de um leitor virtual que é constituído no momento mesmo da escrita. Trata-se de um leitor imaginário com o qual o leitor real deverá estabelecer uma relação. O processo de leitura será, pois, instaurado por esse jogo, essa tensão existente entre o leitor virtual e o leitor real. O que acontece quando certos textos são lidos por estudantes de

\footnotetext{
- Recebido para publicação em janeiro de 2002.

- Professora do Setor de Letras Francesas da Universidade Federal do Rio de Janeiro.
} 
francês língua estrangeira que ignoram, quase sempre, os diferentes contratos que os regem?

Ora, um consenso foi estabelecido, desde os trabalhos de metodologia de francês língua estrangeira (FLE) dos anos 70, segundo o qual aprender uma língua estrangeira pressupõe o aprendizado de uma nova competência comunicativa. Esta seria o resultado não apenas do domínio de uma capacidade propriamente lingüística e textual, mas igualmente o resultado de habilidades e saberes que levam em consideração vários fatores, rotinas e estratégias passíveis de afetar, numa dada comunidade, as trocas interpessoais ${ }^{1}$.

Logo, não é possível pensar a competência comiunicativa em detrimento das representações sociais, concebidas como sistemas de regras psicológicas, culturais e sociais que estruturam a relação do sujeito com o mundo e com os outros. As represen-

'Daniel Coste em seu artigo "Lire le sens", Le Français dans le Monde n'109, 1973 (traduzido em 1988 pela Pontes) afirma que "na leitura, assim como em toda atividade comunicativa em língua materna ou em língua estrangeira, podemos tentar distinguir vários componentes da competência comunicativa:

a) Um componente de capacidade lingüística: saberes e habilidades relativos aos constituintes e aos funcionamentos da língua estrangeira enquanto sistema lingüístico que permite realizar enunciados.

b) Um componente de capacidade textual: saberes e habilidades relativos aos discursos e às mensagens enquanto seqüências organizadas de enunciados (disposiçōes e encadeamentos transfrásticos); retórica e manifestação enunciativa da argumentação.

c) Um componente de capacidade referencial: saberes e habilidades relacionados a domínios de experiência e de conhecimento.

d) Um componente de capacidade de relação: saberes e habilidades relativos às rotinas, estratégias, regulamentos de trocas interpessoais em função de posições, papéis e intençōes dos participantes.

e) Um componente de capacidade situacional: saberes e habilidades relativos a vários outros fatores que podem afetar, numa comunidade e em circunstâncias dadas, as escolhas operadas pelos usuários da linguagem." 
tações "engajam o pertencimento social dos indivíduos com as implicações afetivas e normativas, com as interiorizações de experiências, de práticas, de modelos de conduta e de pensamento, socialmente inculcados e transmitidos pela comunicação [...]" (JODELET, 1989: 36, 37).

Isso coloca um sério problema ao estudante de uma língua estrangeira que habitualmente ignora o que está em jogo nos textos que lê. O perfil dos estudantes do curso de graduação em Letras (português-francês) da Universidade Federal do Rio de Janeiro é formado fundamentalmente por jovens de classe média baixa, advindos de meios culturais desfavorecidos, pouco marcados pelas tradições da cultura erudita.

São, em geral, jovens com pouca experiência de leitura, salvo alguns romances lidos na escola e a prática não cotidiana da leitura de jornais e revistas não especializadas. Apesar disso, eles dispõem de um certo número de categorias interpretativas que adquiriram a partir das mini-séries, das novelas televisivas, dos filmes americanos aos quais assistiram e da familiaridade com as histórias em quadrinho e com as mensagens publicitárias.

Aprender a ler consistirá então em estruturar essas categorias interpretativas, aperfeiçoá-las, torná-las mais apuradas, e até mesmo modificá-las quando isso se mostrar necessário, explorando os dispositivos de decodificação já presentes na mente. (VIGNER, 1979:66).

A questão se coloca nos seguintes termos: se a capacidade de leitura é construída pelo já lido; se, como afirma Vigner (1979:65, 66), "ler não é uma entrada em espaços desconhecidos, como uma certa tradição fez crer, mas a busca de uma confirmação, o estabelecimento quase automático de protoco- 
los de leitura já constituídos, em presença de textos já repertoriados e identificáveis para o leitor", como fazer entrar o estudante de FLE no círculo da leitura? Tal é o desafio com o qual se defronta o professor de língua estrangeira.

Dois conceitos-chave fundamentam a construção de toda leitura: a intertextualidade e a interdiscursividade. Esses dois fenômenonos já são bastante complexos para um leitor de língua materna e sua compreensão e identificação por um leitor estrangeiro parece quase intransponível.

Comecemos por definições. Esses dois fenômenos dizem respeito a uma heterogeneidade, à presença do outro no discurso. Mas se toda intertextualidade supõe uma heterogeneidade, nem toda heterogeneidade enunciativa remete necessariamente à intertextualidade. O próprio do intertexto é mobilizar uma participação ativa do leitor na elaboração do sentido, na medida em que ele deve ser capaz de perceber e de discernir as relações que uma dada obra estabelece com outras, uma vez que "nenhum texto pode ser escrito independentemente do que já foi escrito e ele leva consigo, de forma mais ou menos visível, o vestígio e a memória de uma herança e de uma tradição" (PIEGAY-GROS, 1996:7).

O interdiscurso, por sua vez, constitui a memória discursiva de toda enunciação. É o saber discursivo que torna possível o dizer,

o conjunto de formulações já feitas e já esquecidas que determinam o que dizemos. Para que minhas palavras façam sentido, é preciso que elas já tenham feito sentido. É preciso que o que já foi dito por um dado sujeito numa situação determinada se apague em minha memória e passe ao anonimato, para que "minhas palavras façam sentido" (ORLANDI, 1999: 33, 34). 
O interdiscurso afeta, assim, a forma pela qual o sujeito significa numa determinada situação.

$\mathrm{O}$ que a intertextualidade $\mathrm{e}$ a interdiscursividade salientam é que o estudo da especificidade de um texto e de um discurso supõe que se possa perceber a relação destes com outros textos e outros discursos inscritos na trama de representações própria a cada comunidade cultural. Porém, como lembra Dominique Maingueneau (1998:87),

se intertextualidade e interdiscursividade têm um sentido equivalente, não são, contudo, empregados nos mesmos domínios. É, sobretudo, para tratar da literatura que falamos de intertextualidade, ou, mais amplamente, quando nos referimos a textos no sentido forte, a obras.

Ainda que os fenômenos intertextuais sejam de difícil apreensão para os estudantes de francês língua estrangeira, uma vez que esse trabalho de identificação supõe um vasto conhecimento de obras e autores da literatura francesa, não há dúvida que os estudantes começam a se familiarizar com a intertextualidade desde os primeiros estudos e cursos de literatura francesa. $O$ mesmo não se pode dizer da interdiscursividade, conceito que a ampla maioria desconhece, mesmo ao final da graduação em Letras (português-francês).

Tratando-se de uma memória que circula sub-repticiamente, o interdiscurso tende a passar despercebido sem um exame atento. De forma que proponho examinar aqui alguns fragmentos do discurso gastronômico francês contemporâneo nas revistas especializadas Saveurs, GaultMillau, La Bonne Cuisine e Cuisine et Vins de France. Num primeiro momento, o objetivo será fazê-los refletir sobre o caráter analógico desse discurso, 
que se fundamenta na similitude, ressaltando as representações de França e do povo francês ali presentes.

A questão identitária poderá ser o vetor de entrada nos textos propostos aos estudantes de FLE, pois será possível jogar com as imagens estereotipadas de França que os estrangeiros possuem, mas também com aquelas tecidas pelos próprios franćeses. A França, tal como ela é difundida pela mídia e, notadamente, nos diferentes métodos de aprendizagem, é apresentada como um país simultaneamente moderno e tradicionál, refinado e rústico. À imagem França são associados os monumentos, a bandeira tricolor, a baguete, o queijo, o vinho, a grande restauração, o perfume, a alta costura, o amor pela:cultura. Respeito pela Tradição, de um lado; sofisticação e modernidade, de outro.

Recuperaremos alguns desses clichês nos textos seguintes:

Le Tournedos à la tourangelle

Un plat simple, mais raffiné et élégant, à l'image de la région qui l'a vu naître. (La Bonne Cuisine nº123, p.28)

Dans sa fromagerie de Versailles, Michel Beignon réserve une place de choix aux productions auvergnates. "Dans une région qui a du caractère, les fromages ne peuvent qu'être passionants". (La Bonne Cuisine n¹20, p.56)

Authentique Savoie

Les "Baujus" sont restés farouchement attachés à leurs traditions. Ici, la cuisine est comme les hommes: simple, robuste, chaleureuse. (La Bonne Cuisine $\mathrm{n}^{\circ} 122$, p.36) 
Son écletisme est tel qu'envers et contre tous les diktats de la mode, il n'utilise pas seulement l'huile d'olive qu'il adore, mais aussi le beurre et pouquoi pas la crème. Ainsi crée-t-il avec inspiration, délicatesse, élégance et audace, - toutes qualités que l'on prête au talent parisien - des plats originaux comme la rouille chaude d'étrilles aux chous farcis de tourteau, la viennoise de saint-pierre à la moutarde accompagnée de tagliatelle d'artichaut, les suprêmes de volaille pochées au bouillon de céleri, le jarret de veau à l'étouffée laqué au santenay, le sablé au chocolat mi-cuit escorté du biscuit aux noisettes grillées... qui pourraient bien devenir de grands classiques de la cuisine francilienne. (GaultMillau no304, p.62)

É do conhecimento de todos que a França mantém uma relação muito particular com a gastronomia. O discurso gastronômico se inscreve em formações discursivas ${ }^{2}$ que privilegiam a inserção e a difusão de alguns mitos fundadores de uma certa idéia de nação francesa, assim como de uma determinada imagem de povo francês.

De fato, o que está em jogo na gastronomia é a construção da identidade social e nacional. Nas palavras do sociólogo Claude Fischler (1990: 69), o homem come no interior de uma cultura, o que significa que cada cultura incorpora o indivíduo

O conceito de formação discursiva designa todo sistema de regras que fundamenta a unidade de um conjunto de enunciados sociohistoricamente circunscrito. Quando se fala de formação discursiva, considera-se que "para uma sociedade, uma posição e um momento determinados, só uma parte do dizível é acessível, e que este dizível forma sistema e delimita uma identidade" (MAINGUENEAU, 1984:5, 6). 
ao social por seu sistema de práticas e representações. Os sistemas culinários não são neutros. Eles correspondem antes a múltiplas visões do mundo que atribuem sentido ao homem e ao universo, situando um em relação ao outro.

Resultado do cruzamento de um meio e de uma história, a cozinha responde, mais do que qualquer outra, a uma necessidade vital, ela passa necessariamente por um rito coletivo (a refeição, seu cardápio), uma tradição (a receita e a forma), uma discriminação (o produto, o comentário). Compreende-se que ela constitua uma das expressóes mais específicas de uma etnia e, nos Tempos modernos, de uma nação (ORY, 1992: 823).

As qualificações presentes nos fragmentos de textos acima constroem imagens do povo francês sobre dois eixos que correspondem a duas formações discursivas ${ }^{3}$ relativas às duas vertentes da gastronomia francesa. Com efeito, a arte da cozinha na França repousa em duas fontes: a Alta Gastronomia, promovida pelas classes dominantes das diversas épocas, que valoriza a invenção e a experimentação, e a Cozinha popular, de origem camponesa, ligada à região e à terra, aos produtos locais, e cujo saber-fazer ancestral foi transmitido de geração em geração pela força da imitação e do hábito. De um lado, como atestam as citações apresentadas, elegância, refinamento, inspiração, delicadeza, audácia, originalidade; de outro, simplicidade, robustez, calor; ambas as qualidades apontando para um povo e um país "apaixonantes" que, na conciliação de qualidades opostas, "têm muita personalidade".

${ }^{3}$ Essas formações discursivas são constitutivas do interdiscurso gastronômico francês contemporâneo. 
Um outro aspecto fundamental a ser ressaltado nos excertos acima é a circularidade do raciocínio analógico apresentado:

\author{
Tal prato, tal regiāo ( $1^{\mathrm{a}}$ citação) \\ Tal região, tal produto ( $2^{\mathrm{a}}$ citação) \\ Tal cozinha, tais homens ( $3^{\text {a }}$ citação) \\ Tal homem, tal região $\left(4^{a} \text { citação }\right)^{4}$
}

A analogia se dá de forma que se possam combinar em pares todos os termos (prato, região, cozinha,homem) entre si em qualquer direção. Tudo converge para um imaginário essencialista onde a Essência (Ser) explica a Existência (Fazer) e onde a Existência não faz senão confirmar a Essência. Na circularidade desse raciocínio, reforçam-se as seguintes representações: o homem francês é excepcional. Porque é excepcional, tudo o que faz é de extremo valor; ou ainda: a terra francesa é extraordinária. Porque é extraordinária tudo o que dela é oriundo é de extrema qualidade...

Essa crença está igualmente presente em um dos célebres aforismos de Brillat-Savarin (1965: 23): "Dize-me o que comes e te direi quem és". Aqui mais uma vez reitera-se a idéia de que a essência precede a existência, ou seja que o Fazer não faz senão confirmar o Ser. O ato de comer é uma extensão e uma confirmação do ser. Estamos longe aqui do humanismo existencialista de Sartre.

Aqui observa-se a simetria inversa daquela proposta por Montesquieu (1748:616), em seu célebre Esprit des lois. Para este autor, o clima é o fator capital na construção do espirito geral de um país ou de uma região. É ele que modela o temperamento dos diversos povos e sua maneira de viver. A concepção de Montesquieu salienta as seguintes analogias: tal clima, tal região; tal clima (ou tal região), tais homens. 
Pode-se dizer da concepção de sujeito cara ao discurso crítico gastronômico o mesmo que o sociólogo Pierre Bourdieu (1979:23) diz da nobreza:

As nobrezas são essencialistas: tomando a existência por uma emanação da essência, elas nāo consideram os atos em si mesmos [...] elas só lhes atribuem valor na medida em que estes manifestam claramente, nas mínimas nuances, que eles têm por único princípio a perpetuação e a ilustração da essência em virtude da qual eles se realizam.

Nas revistas gastronômicas, constata-se assim uma personificação da cozinba e do prato, estes últimos atestando as qualidades do povo francês:

\section{Le plaisir des soupes d'été}

Rustiques, gaillardes et savoureuses, elles furent longtemps méprisées au profit des potages, consommés et veloutés, plus sophistiqués. (La Bonne Cuisine n²124, p.14)

De tradição camponesa, as sopas foram, por muito tempo, a base da alimentação do francês. Se o camponês é visto como rustique e gaillard, nada mais "natural" do que transferir sua "natureza" para o prato em que come. Os consommés e os véloutés são mais sofisticados pela simples razão de que fazem parte dos hábitos alimentares dos citadinos, considerados mais sofisticados.

No início dos anos 80, o grande interesse pela cozinha regional (cuisine de terroir) leva os chefs e a indústria agroalimentar a explorarem intensamente a geografia culinária francesa. A importância da região, de sua cozinha e de seus produtos, 
originados da terra e de um saber-fazer local é salientada nas revistas estudadas. Lugar mítico que guarda os valores da tradição, da qualidade e da autenticidade, a cozinha regional é a prova da excelência não somente da tradição gastronômica francesa, mas também da qualidade da terra francesa e de seu povo.

As culturas locais, seus pratos e receitas, são apresentadas como tendo o mesmo temperamento do meio que elas refletem. Os argumentos em favor das cozinhas regionais se multiplicam e se fundamentam em três pontos principais: a diversidade e a docilidade naturais da terra e do clima, a suculência e a variedade dos produtos e a qualidade dos homens e de seu saber-fazer (CSERGO, 1996). Isso significa que é graças à excelência da cozinha francesa que se constroem imagens positivas da terra, do clima, dos produtos e dos homens, a qualidade da cozinha sendo a mola principal de todas as outras qualificações.

O discurso gastronômico francês faz valer a saga de um povo unido por um passado que se faz presente, reafirmando a perfeição de seu gênio. $O$ produto e a cozinha são apresentados como a expressão do gênio desse povo:

En matière de cochonnailles, le génie inventif de notre vieux pays de gourmands se montra particulièrement fécond. L'immense éventail des spécialités régionales en fait foi. Il varie au gré des espèces porcines du climat, des produits locaux, des méthodes de conservation et des savoir-faire ancestraux. (La Bonne Cuisine $\mathrm{n}^{\circ} 120$, p.18)

Lever de rideau privilégié du théâtre culinaire, la terrine se distingue par ses distributions pleines de fantaisie, ses décors éphémères et ses costumes en gelée de gala. C'est un mets national qui mérite le respect: imaginerait- 
on un chef sans terrine? C'est pourquoi 19 pages sont consacrées, dans le grand dossier du mois, à cette trouvaille bistorique des génies de la casserole (Cuisine et Vins de France $\mathrm{n}^{\circ} 10$, p.5).

Esse gênio se traduz pela "excepcionalidade" do saberfazer e da arte de viver à francesa:

Du Nord au Sud, la ronde ds 400 fromages!

Un peuple capable de produire 400 fromages différents est peut-être ingouvernable...mais quel art de vivre! (Guide Loisirs de l'été 94, p.38, Saveurs $n^{\circ} 42$ )

Este texto apresenta uma das versões de um diálogo atribuído a Churchill e de Gaule e exprime um dos mais vigorosos clichês sobre a identidade francesa: o mito da unidade na diversidade. Em seu artigo "O local - una e divisível" (1992), o historiador Thierry Gasnier percorre esse mito no tempo.

Desde a Revolução, as representações da França oscilam na tensão entre a unidade e a multiplicidade, o universal e o particular. A nação, tal como foi inicialmente concebida pela Revolução, constituía o núcleo, o centro organizador que comandava a divisão territorial, a partir de então, em departamentos. A nação deveria dar ao particular coesão e coerência, o todo sendo superior ao conjunto de suas partes. Contudo, a irredutibilidade e a permanência da cultura local, seu profundo enraizamento dissuadiram qualquer iniciativa no sentido de atenuar essas especificidades.

Com a Terceira República, o dogma da unidade se perde em proveito da particularidade e da fragmentação. A idéia da unidade da França dá lugar a uma concepção de França plural. Embora a centralização do Estado se mantenha forte, a 
República se abre para uma política de valorização do local. "O local torna-se o fundamento da definição da França" (GASNIER, 1992:503), sua especificidade não acarreta o desmantelaménto do país, mas reforça a solidariedade entre as partes. "A França se situa na interseção das diferenças dos elementos que a compõem" (GASNIER, 1992:504).

A diversidade constitui, assim, um tesouro nacional, como o confirma a seguinte citação:

L'aventure est au bout du chemin

Le plus grand trésor de la France, c'est sa diversité! Un hexagone presque parfait, avec la Corse en point d'exclamation. Lande, Bocage, forêt profonde, vallée fraîche et romantique, plage de sable blond...Autant de joyaux qui vous espèrent. Alors, ne les faites pas attendre, c'est facile, prenez la prochaine sortie de l'autoroute...

Connaissez-vous un pays qui supporte le soleil, la brume, les tempêtes avec la même sérénité, toujours doux, toujours riant, toujours vert; un pays naturellement dessiné, d'un côté par les plus hautes montagnes d'Europe, et de l'autre par l'océan immense et fascinant; un pays qui ne se laisse jamais aller à la monotonie des mornes plaines ou à la tristesse des plateaux infinis; un pays aussi latin que saxon qui depuis des millénaires engrange les oeuvres d'art inspirées par ses paysages et ses hommes? ... Ce pays, c'est le vôtre et si vous doutez encore d'être né au paradis, il est temps de quitter votre cocon, aussi douillet soit-il, d'oublier les foules des autoroutes et leurs terminus standardisés, et de tenter une véritable aventure, de villages en vignobles, de forêts en manoirs, de grottes en sommets... (Le guide loisirs de l'été 94, p. 7, Saveurs $\left.\mathrm{n}^{\circ} 42\right)$ 
À idéia de diversidade se associa um mito antigo e tenaz, segundo o qual a França é um "país de eleição", "um verdadeiro paraíso terrestre" que concentra a plenitude cósmica de rios, mares, florestas, vales, planícies, planaltos e montanhas. Nessa perspectiva, conhecer a França torna-se uma verdadeira aventurá e o sentimento de ser francês se revitaliza.

Sob o nome França surgem a terra e suas imagens. A terra francesa, inteiramente domesticada, tem uma reputação de riqueza e fertilidade. Sua imagem idealizada persiste desde a Gália romanizada. Como fator geográfico, valoriza-se a imagem de uma França que goza de uma situação espacial excepcional, ponto de convergência entre a Europa central e a Espanha, entre o mar Mediterrâneo e o Oceano Atlântico. Esse país, visto como privilegiado, dispóe de uma complementaridade dos climas.

A leitura desse texto suscita, por um lado, uma certa curiosidade do estudante brasileiro; por outro, um sentimento de estranheza, pois os brasileiros sempre viveram na crença de que eles são o verdadeiro "paraíso terrestre"... Se a França, país de dimensões territoriais reduzidas, abriga toda essa diversidade, o Brasil, país de dimensão continental, poderia, com muito mais "pertinência", reivindicar esse estatuto. Além disso, a idéia de um país "toujours doux, toujours riant, toujours vert et naturellement dessiné" sempre perseguiu as representações do Brasil desde sua descoberta em 1500.

Situarei historicamente esse mito brasileiro que está na base de uma certa formação discursiva constitutiva do espírito de identidade e de nacionalidade brasileiras. A filósofa Marilena Chauí publicou em 2000 um grande estudo intitulado $O$ mito fundador do Brasil onde ela trata dessa questão.

A América era para os viajantes e os evangelizadores uma 
construção simbólica e imaginária, antes de ser um conceito geopolítico, militar e econômico. O Novo Mundo já existia, pois, não como realidade cultural e geográfica, mas como texto. A descoberta e o conhecimento do Brasil foram apenas a confirmação da exatidão dos antigos textos. O Brasil representava a sede imaginária do Paraíso Terrestre, profetizado por Daniel, o que explica que os brasileiros vivam ainda hoje sob a presença difusa de uma narrativa de origem que foi elaborada no período da conquista, e que não cessa desde então de se repetir, pois ela constitui o mito fundador do Brasil.

"Um mito fundador, como toda fondatio, impõe um laço interno com o passado como origem, ou seja com um passado que não cessa jamais e que, por isso, não permite o trabalho da diferença temporal, o que significa que esse passado é eternamente presente" (CHAUÍ, 2000). Pelas circunstâncias históricas de sua construção inicial, o mito fundador do Brasil tem certos componentes que se entrecruzam, determinando não somente a imagem que os brasileiros têm de si mesmos, mas também sua relação com a política e com a história. Um dos elementos constitutivos desse mito é a "visão do paraíso". O Brasil, nos escritos que se seguem à sua descoberta, é descrito como um imenso e perfeito jardim, presenteado com uma vegetação bela e abundante, um céu sempre estrelado, mares tão verdes quanto profundos, uma diversidade de animais amáveis e dóceis, uma temperatura sempre agradável, algo como uma eterna primavera. Para um leitor dos séculos XVI e XVII, esse retrato confirma que se trata realmente do paraíso terrestre reencontrado.

A bandeira brasileira, por sua vez, não exprime nem a política nem a história. É um símbolo da natureza: o verde representa as florestas; o azul, o céu; o amarelo, o ouro; e o branco, a ordem (única concessão à Cultura). $\mathrm{O}$ mesmo fenômeno pode ser observado no hino nacional do Brasil que canta os 
mares mais verdes, os céus mais azuis, os campos mais floridos. Um de seus versos afirma que o Brasil é um gigante "deitado eternamente em berço esplêndido". Trata-se evidentemente da afirmação da Natureza, enquanto paraíso ou berço do mundo, eterna em seu esplendor.

Essa produção mítica do país-paraíso nos persuade de que nossa identidade e grandeza são pré-determinadas no plano natural e difunde a imagem segundo a qual nós somos sensíveis, sensuais, ternos, acolhedores, alegres e sobretudo não-violentos. Esse elemento da construção mítica do Brasil nos lança e nos conserva no reino da Natureza, nos fazendo escapar do mundo da história (CHAUÍ, 2000: 10).

Um outro elemento importante na produção desse mito fundador diz respeito à história teológica ou providencial, segundo a qual o Brasil seria a realização da vontade divina. Nessa perspectiva, o Brasil é uma "terra abençoada por Deus", a natureza paradisíaca sendo o signo da Providência de um povo eleito cujo futuro feliz estaria para sempre assegurado.

Esse pequeno histórico, baseado no livro de Chauí, nos mostra como a leitura de um texto pode se prestar a um trabalho de contraste, que diga respeito às formações discursivas que fundam a identidade de dois países tão diferentes, marcados por percursos sócio-históricos tão diversos que pareceriam, à primeira vista, inconciliáveis. Contudo, procurei demonstrar que as idéias míticas de diversidade e de paraíso terrestre existem nessas duas culturas, concorrendo para a construção da imagem de nação de cada um desses países.

A despeito das dificuldades suscitadas pela identificação e compreensão de fragmentos interdiscursivos em textos de francês língua estrangeira, o estudo das representações da França presentes no último texto proposto permitiu que um diálogo se 
estabelecesse entre estas e as representações da França e de Brasil que os estudantes brasileiros possuem. Isso nos permite concluir com uma citação de Bakhtine, na sua Estética da criação verbal (1984: 169):

Existe uma imagem muito viva, mas parcial e por conseqüência falsa, segundo a qual para melhor compreender uma cultura estrangeira, dever-se-ia de alguma forma habitá-la, e esquecendo a sua própria, olhar o mundo através dos olhos dessa cultura. Como já o disse, uma tal imagem é parcial. Evidentemente, entrar numa certa medida numa cultura estrangeira, olhar o mundo através de seus olhos, é um momento necessário no processo de sua compreensão; mas se esta se esgotasse só nesse momento, ela seria um simples desdobramento e não traria nada de novo nem de enriquecedor. A compreensāo criadora não renuncia a si, a seu lugar no tempo, à sua cultura, e não esquece nada. A grande contribuição da compreensão é a exotopia daquele que compreende - no tempo, no espaço, na cultura - em relação ao que ele quer compreender criativamente. [...] No domínio da cultura, a exotopia é a mais potente alavanca de compreensão. Não é senão aos olhos de uma cultura outra que a cultura estrangeira se revela de forma mais completa e mais profunda (mas jamais de forma exaustiva), pois virão outras culturas que verão $e$ compreenderão mais ainda.

Résumé: Dans le jeu de production-interprétation du sens inbérent à toute lecture, le sujet-lecteur inscrit sa vision du monde et son bistoire, désignées par l'idéologie. Ce processus se beurte à des difficultés particulières quand on a affaire à la lecture en langue étrangère. Cet article propose une discussion sur l'interprétation de l'interdiscours, l'un des aspects fondamentaux de la production signifiante, établie à partir de la tension entre des lieux socioculturels marqués par l'altérité. 


\section{Referências bibliográficas}

BAKHTINE, M. Esthétique de la création verbale. Paris: Gallimard, 1984.

BOILEAU, Nicolas. Oeuvres complètes. Bibliothèque de la Pléiade. Paris: Gallimard, 1966.

BOURDIEU, Pierre. La distinction. Critique sociale du jugement. Paris: Minụit, 1979.

BRILLAT-SAVARIN, Jean-Anthelme. Pbysiologie du goût. Paris: Julliard, 1965.

CHAUI, Marilena. O mito fundador do Brasil. Folha de São Paulo. Mais! São Paulo, Domingo, 26 de março de 2000.

COSTE, D. et alii. O texto: leitura e escrita. Campinas, São Paulo: Pontes, 1988.

CSERGO, Julia. Nostalgies du terroir. In: Mille et une bouches. Cuisines et identités Culturelles. Revue Mangeurs n¹54. Paris: Autrement, 1995.

DUPRONT, Alphonse. Du sentiment national. In: La France et les Français. Encyclopédie de la Pléiade. Paris: Gallimard, 1972.

FISCHLER, Claude. L'bomnivore. Paris: Odile Jacob, 1990.

GALISSON, R. \& COSTE, D. Dictionnaire de didactique des langues. Paris: Hachette, 1976.

GASNIER, Thierry. Le local - une et divisible. In: NORA, Pierre (dir). Les lieux de mémoire. t.III, Les France, 2. Traditions. Paris: Gallimard, 1992.

JODELET, Denise et alii. Les représentations sociales. Paris: PUF, 1989.

MAINGUENEAU, Dominique. Genèses du discours. Bruxelles:

Pierre Mardaga, 1984.

_. Les termes clés de l'analyse du discours. Paris: Seuil, 1996. 
MONTESQUIEU. De l'esprit des lois (1758). In: Oeuvres Complètes. Paris: Seuil, 1964.

ORLANDI, Eni Pulcinelli. Discurso E Leitura. São Paulo, Cortez; Campinas, S.P.: Editora da Universidade Estadual de Campinas, 1988.

. Análise de discurso. Princípios \& Procedimentos. Campinas: Pontes, 1999.

ORY, Pascal. La gastronomie. In: NORA, Pierre (dir). Les lieux de mémoire. t.III, Les France, 2. Traditions. Paris: Gallimard, 1992.

PIÉGAY-GROS, Nathalie. Introduction à l'intertextualité. Paris: Dunod, 1996.

VIGNER, Gérard. Lire: du texte au sens. Paris: CLE International, 1979. 